\title{
EXISTENCIALIDADE DA CRIANÇA COM AIDS: PERSPECTIVAS PARA O CUIDADO DE ENFERMAGEM ${ }^{a}$
}

\author{
Existentially of the Child with AIDS: \\ Perspectives for the Nursing Care \\ Existencialidad del Niño con SIDA: \\ Perspectivas Para el Cuidado de Enfermería
}

Cristiane Cardoso de Paula ${ }^{1}$

Maria da Graça Oliveira Crossetti

\begin{abstract}
Resumo
Este artigo objetiva apresentar reflexões acerca do cuidado de Enfermagem que emergiram da dissertação de mestrado "Encontro de cuidado, vivido e dialogado, da equipe de Enfermagem com o ser-criança que convive com AIDS", que buscou compreender o significado deste cuidado sob o olhar da Teoria de Enfermagem Humanística de Paterson e Zderad. Constituiuse em um estudo qualitativo-fenomenológico com análise hermenêutica. Desvelou-se a existencialidade da criança com AIDS: seres de relação com os outros e com o mundo, fazendo destaque ao mundo do cuidado, que possuem singularidade marcada pela temporalidade e historicidade, que têm familiares que cuidam e que necessitam de cuidados. Concluiu-se que, no encontro genuíno do cuidado de Enfermagem, faz-se essencial a compreensão da existencialidade dessa criança e de sua família como unidade de cuidado, vislumbrando o estar-melhor na relação intersubjetiva de presença e respeito.
\end{abstract}

Palavras-chave: Cuidado da Criança. Cuidados de Enfermagem. Teoria de Enfermagem. Síndrome da Imunodeficiência Adquirida.

Abstract

The focus of this study is to present some reflections about the Nursing care which emerged from the dissertation "A meeting of lived and dialogued care of the nursing team with the child being who lives with AIDS". This work aim was to understand the meaning of this care in relation to the Humanistic Nursing Theory by Paterson and Zderad. It was a phenomenological and qualitative study with hermeneutic analysis. It was showed the perception regarding the existentiality of the child being who lives with AIDS: children maintain a relationship with other people and with the world (mainly the care world), have a singularity marked by temporality and historicity, and consider their relatives as people who take care and need care. In the genuine meeting of Nursing care, it was concluded that it is essential the understanding of this child being existentiality as well as of his/her relatives as the care unity, highlighting the better being concerning intersubjective relationship of presence and respect.

Keywords: Child Care. Nursing Care. Nursing Theory. Acquired Immunodeficiency Syndrome.

\section{Resumen}

Este artículo tiene como foco presentar algunas reflexiones acerca del cuidado de Enfermería que emergieron de la disertación de maestría "Encuentro de cuidado, vivido y dialogado, del equipo de enfermería con el ser-niño que convive con el SIDA", que tuvo como objetivo comprender el significado de este cuidado bajo la mirada de la Teoría de Enfermería Humanística de Paterson y Zderad. Se constituyó en un estudio cualitativo-fenomenológico con análisis hermenéutico. Se desveló la percepción referente a la existencialidad del niño que convive con el SIDA: seres de relación con los otros y con el mundo, destacando al mundo del cuidado, que poseen singularidad señalada por la temporalidad e historicidad, y que tienen familiares que cuidan y que necesitan de cuidados. Se concluyó que en el encuentro genuino de cuidado en Enfermería se torna esencial la comprensión de la existencialidad de este niño que convive con el sida y de su familia como unidad de cuidado, vislumbrando el estar-mejor en la relación intersubjetiva de presencia y respeto.

Palabras clave: Cuidado del Niño. Cuidados de Enfermería. Teoría de Enfermería. Síndrome de Inmunodeficiencia Adquirida. 


\section{INTRODUÇÃO}

Ao refletir acerca do contexto experienciado pela equipe de Enfermagem, frente ao aos desafios que emergem no cuidado à criança com a Síndrome da Imunodeficiência Adquirida (AIDS), tem-se a justificativa da necessidade e relevância de estudos que se desenvolvam com o intuito de compreender o mundo-vida com esta doença. Busca-se, assim, alcançar ações comprometidas e eficazes na luta contra esta epidemia, vislumbrando uma vida com melhor qualidade para as pessoas com a AIDS.

Nessa perspectiva, escolheu-se a Teoria de Enfermagem Humanística ${ }^{1}$ como referencial para a construção do saber e fazer referente ao cuidado, pois suas bases existenciais permitem a compreensão das relações estabelecidas entre os seres humanos. Também pela definição da Enfermagem como uma reciprocidade vivida no encontro de cuidado e que vislumbra um estar-melhor.

Assim, o presente estudo apresenta algumas perspectivas para o cuidado de Enfermagem, fundamentadas em Paterson e Zderad ${ }^{1}$, que emergiram da compreensão do significado de cuidar da criança com AIDS.

\section{CAMINHO METODOLÓGICO}

0 estudo caracteriza-se como pesquisa qualitativa de abordagem fenomenológica, a partir da Teoria de Enfermagem Humanística', que busca salientar aspectos da existencialidade no mundo vivido e compreender a essência dos fenômenos.

0 projeto foi encaminhado ao Comitê de Ética em Pesquisa (CEP) da Universidade Federal de Santa Maria (UFSM/RS), conforme a Resolução n 196/96², contando com um Termo de Consentimento Livre e Esclarecido, respeitando a participação voluntária, e a não-interferência no seu vínculo empregatício com a instituição e não-revelação de sua identidade, usando apenas os códigos: C1-C8.

Com a aprovação pelo CEP, o estudo foi desenvolvido na Unidade de Internação Pediátrica (UIP) do Hospital Universitário de Santa Maria (HUSM). Teve como depoentes oito cuidadores da equipe, selecionados aleatoriamente entre enfermeiros e auxiliares de enfermagem. Critério de inclusão: profissional em exercício do cuidado à criança com AIDS. 0 número de depoentes configurou-se quando as entrevistas indicaram o mostrar-se do fenômeno em suas estruturas essenciais, ou seja, quando se expressou o núcleo invariante do desvelamento do fenômeno ${ }^{3}$.

0 acesso aos depoentes deu-se com a ambientação $0^{4}$ da pesquisadora na UIP, por meio da aproximação da equipe de Enfermagem e pelo convite àquelas que cuidam das crianças com AIDS para participar do estudo. A coleta de informações foi por entrevista ${ }^{5}$, que possibilitou um conhecimento do ser, visando à totalidade do que se quer conhecer. A questão norteadora foi: conte-me, como é para você cuidar de uma criança com AIDS? 0 ambiente foi uma sala, na própria UIP, que possibilitava a privacidade necessária para que a relação face-a-face na entrevista se desenvolvesse.

A partir dos depoimentos, foi desenvolvida a análise hermenêutica ${ }^{6}$, que visa à descoberta do sentido, na compreensão da existência humana, em busca de interpretar a linguagem pensada não através do que diz, mas do que esconde, a fim de apreender as experiências e as vivências em sua totalidade.

Esta análise seguiu as fases: leitura inicial (primeiro contato com os depoimentos para a compreensão dos significados iniciais); distanciamento (o pesquisador absteve-se de suas crenças e/ou preconceitos para uma reflexão descontaminada do que emergiu dos depoimentos); análise estrutural (releitura profunda e crítica que buscou o significado do que estava oculto nos depoimentos para o desenvolvimento dos temas e subtemas). Seguiram-se a identificação da metáfora (a partir dos temas e subtemas, ocorreu a interpretação hermenêutica dos depoimentos) e apropriação (o pesquisador apropriou-se do que é desvelado dos depoimentos fazendo a articulação com a prática do cuidado) ${ }^{7,8}$.

Um dos temas que emergiu neste estudo foi a existencialidade do ser-criança com AIDS, com os seguintes subtemas: ser-no-mundo-com-o-outro; expressividade no mundo do cuidado; temporalidade e historicidade; estar-com do ser-familiar; ser-familiar como um ser de cuidado, os quais serão apresentados neste artigo.

\section{A EXISTENCIALIDADE DO SER-CRIANÇA COM AIDS}

0 ser que cuida compreende a existencialidade da criança com AIDS, com base na vivência de cuidado, com um ser-sendo em um em seu processo do desenvolvimento infantil. Entende que este vir-a-ser contempla as dimensões das experiências e vivências da criança, como ser de relação (ser-com) consigo, com os outros (destaca a importância do estar-junto da família) e com o mundo (mundo-da-vida, mundo-da-família e mundodo-hospital). Revela a expressividade da criança no mundo do cuidado. E, considera que essas dimensões desvelam a temporalidade e historicidade da criança e suas possibilidades - para estar melhor -, e suas potencialidades - para ser mais.

\section{Ser-no-mundo-com-o-outro}

Este modo de existencialidade apresenta a criança com AIDS como um ser-no-mundo-com-o-outro que necessita de ajuda e cuidado em seu processo de vir-a-ser. Entende-se que o ser humano mantém-se em relação consigo, com o outro e com o mundo e que, em sua condição existencial de ser-com, busca conhecimento de si por meio do conhecimento do outro e do mundo. Assim, o ser tornase mais na condição de abertura ao encontro, no qual tem a necessidade de conhecer e de compreender o outro e o contexto em que a vivência é compartilhada.

As crianças que tem AIDS não são diferentes das outras crianças. Eles em si não são diferentes(C8)

Criança é criança! Independente da doença, criança é um serzinho que encanta... é um encanto trabalhar com eles, a gente é feliz de poder cuidar dele (C4)

Esta compreensão vai ao encontro da unicidade existencial, sendo esta caracterizada pela singularidade das vivências e experiências ${ }^{1}$. Não se contrapondo a esse perceber, mas corroborando a sua complexidade, apresenta, ainda, o 
entendimento de que os existenciais básicos do ser humano são os mesmos, o que lhes confere a característica de ser-nomundo-com-o-outro, que possui potencialidades e possibilidades independente da sua doença'.

Sob o olhar da Teoria de Enfermagem Humanística, a saúde e a doença são modos de existir integrantes da existencialidade do humano. 0 processo de adoecimento, como uma situação vivida, confere restrições nas relações ${ }^{1}$; no entanto, o ser humano quando doente continua construindo sua existência e suas relações com os outros e com o mundo.

Nos depoimentos, o ser que cuida expressa sua maneira de compreender a criança como existencialmente é, para além de sua doença, o que possibilita a aber tura ao encontro de cuidado, essencial às relações genuínas, em um mundo compartilhado ${ }^{1}$.

A relação genuína ocorre no diálogo vivido existencialmente entre o EU e o TU ${ }^{9}$, em que Paterson e Zderad referem existir possibilidade do cuidado autêntico, quando o ser é compreendido em seu mundo-da-vida singular, com suas experiências e vivências próprias de sua historicidade e temporalidade ${ }^{1}$

a gente vê que elas têm vontade de viver, que querem algo mais (C1)

Compreende-se que o transcender da doença não limita a criança, que continua a possuir necessidades que são singulares, visto que é um ser-sendo. Desvela-se que a doença não encerra o vir-a-ser na infância; a criança mantém sua existencialidade como possuidora de potencialidades para ser mais. Abrem-se, mediados por este estar-com, horizontes para o cuidado de Enfermagem, no qual o ser que cuida tem a possibilidade de ajudálo, por meio da presença autêntica e, em especial, da afetividade, que transcende o cuidado terapêutico dos medicamentos, intervenções, procedimentos, curativos, normas ou rotinas.

São crianças como quaisquer outras, tem uns que são mais retraídos, outros em questão de saúde são mais comprometidos. Tem muito a ver com condição familiar, o cuidado que têm em casa, varia muito do ponto de origem, tem uns que são mais fáceis, tem uns que tu tem que praticamente que forçar a tomar a medicação, o coquetel, mas isso varia muito de cada criança, não dá para dizer que todas são iguais ou que têm os mesmos problemas, as mesmas dificuldades (C6)

Percebe-se a necessidade de compreender a totalidade do mundo-da-vida da criança, visto que o ser não deve ser visto de forma fragmentada, sendo reconhecido apenas no prisma de sua doença, em detrimento de seu mundo-da-família. Ao vivenciar o processo de adoecimento e ingressar no mundo-do-hospital, essas dimensões constituem um espaço e tempo existenciais ${ }^{1}$ que fazem parte de um âmbito maior: o mundo-da-vida integral de cada ser.

Tem-se, ainda, a experiência do estar-com no processo de adoecimento e na inserção do hospital no mundo da criança. A partir desta relação com o outro, o ser que cuida desenvolve uma maneira de percebê-lo.

Uma criança especial tem que ter um tratamento especial... se a criança tem uma pneumonia, tu dá remédio, ela fica boa e vai para casa bem. Essas crianças não são assim... passam por tudo: nem sabem direito o que têm, vão e vêm da casa para o hospital, do hospital para casa, têm que tomar um monte de medicação, perdem a mãe... Como falar com a criança sobre isso? Como explicar? Como convencer a tomar remédio para continuar vivendo? O que passa na cabecinha delas? (C6)

No encontro de cuidado, cada ser necessita ser percebido como único e se estabelece uma relação singular para que ambos possam se conhecer, o ser que cuida e a criança, em sua existencialidade. $E$ é neste encontro que emergem as inquietações e os questionamentos de como melhor desenvolver o cuidado ${ }^{1}$.

\section{Expressividade no mundo do cuidado}

0 ser que cuida refere que a criança com AIDS, ao estar no mundo do cuidado, tem sua expressividade como: carência, agressividade, distanciamento, além de revelar um olhar triste e a existência de um mundo que lhe é próprio.

A infância dessas crianças é muito difícil, nem sei se têm infância de verdade. Logo que começam o tratamento é tão difícil que acho que perdem parte daquela infância, não vivem direito, não brincam... É diferente da criança saudável, ou que tem doença simples como pneumonia ou desidratação, que passa a fase da doença e volta tudo ao normal. Essa criança, a doença vai acompanhar o resto da vida, vai precisar de cuidado, medicação, acompanhamento... que infância vai ter? (C6)

Ao considerar que o ser humano possui, como parte integrante e sua existencialidade, potencialidades e limitações ${ }^{1}$, e que estas podem ser entendidas, por exemplo, como uma doença crônica, é possível compreender que a criança precisa ser percebida na integralidade de sua existência, para além de sua doente. Neste sentido, o ser que cuida, ao vislumbrar a infância apenas na ausência de doença, limita a criança em suas potencialidades. Portanto, o cuidado de Enfermagem precisa ir além dessas limitações, considerando o potencial para ser mais e estar melhor mesmo em casos rotulados como "caso terminal", "sin esperanza" e "crónico"1, p.30.

Paterson e Zderad ${ }^{1}$ entendem que, mesmo no mundo-dohospital, o ser humano tem possibilidades de buscar um bemviver por meio da inter-relação no encontro de cuidado, expresso no existencial básico de ser de relação: ser-no-mundo-com-ooutro. Alicerçado neste pensamento, tem-se que a infância pode ser vivenciada no hospital, e um caminho para que isto se torne realidade pode ser a Enfermagem Humanística'.

A criança precisa ser compreendida como um ser-sendo, em processo de vir-a-ser, para o qual se faz essencial ter a possibilidade de experienciar o que é próprio da infância, e que o viver com uma doença não impossibilita, ou não deve restringir-lhe esta necessidade.

São crianças, têm direito a ter infância. A gente tem que respeitar e entender que isso é importante, fazer tudo para ajudar a estar bem para viver bem e brincar, sorrir, aprender... Tem que lembrar que antes de qualquer coisa eles são crianças, não são só doentinhos, eles precisam de coisas de crianças, sonhos, brincadeiras, carinho, sorriso, abraço, atenção, proteção, amor... acho que cuidar é 
também dar isso, é ver que a criança precisa, não só remédio... ouvir, contar história... (C6)

A relação entre ser que cuida e a criança revela a necessidade de fazer parte do mundo da criança, que desvela o cuidado como um mundo compartilhado, construído a partir da singularidade da existencialidade de cada ser e da interrelação do seu mundo-da-vida, mundo-da-família e mundo-dohospital. 0 ser que cuida é facilitador no processo de escolhas para o potencial do vir-a-ser da criança; para tanto, há a necessidade do reconhecimento da unicidade do ser em seu espaço e tempo vividos ${ }^{1}$. Mediado por esta compreensão, que orienta o modo de ser-com, é possível o desenvolvimento de uma relação genuína de com-unidade ${ }^{10}$, que abre horizontes à busca do estar melhor.

Tem muitas crianças que têm o problema da AIDS que são carentes de afeto, porque muitas vezes os pais já se foram... querem atenção, tão sempre atrás da gente, (C3)

Paterson e $Z_{\text {derad }}{ }^{1}$ entendem que o ser humano compreende o outro ao estabelecer uma relação. Por meio desta relação é que o encontro de cuidado se desenvolve, sendo considerada essencial à Enfermagem. Nesta transação interhumana e intersubjetiva ${ }^{1}$, um ser revela-se ao outro pela expressividade, em palavras, gestos, olhar ou silêncio. No diálogo vivido por cada ser em sua unicidade, faz-se necessário estar aber to e atento ao que é expresso, pois assim percebe-se o que a criança necessita e o que é possível fazer para ajudá-la.

Tem umas que se tornam agressivas, eu não sei porque, em função já de terem isso, serem excluídas, perdas... Tu não consegue cativar ela tão fácil como seria outra criança. A criança com AIDS tem essa diferença de muitas vezes não ter os pais junto, é a tia ou a vó que cuida (C3)

Esses pacientes passam por dificuldades, problemas de família, (...) são crianças rebeldes, que não querem se submeter às ordens da Enfermagem. A gente diz: 'vamos tomar banho', e a criança responde 'agora eu não quero', ou 'tem que almoçar', e a criança continua: 'não quero'. Teve momentos muito difíceis. 'Tem que tomar teu remédio, minha filha', aí a criança fecha a cara e não toma (C1)

Não acho que as crianças são diferentes, mas a gente sente que elas são diferentes (...) diferente no jeito delas, se tu chegar numa outra criança que não tem AIDS, conversar com ela, tu vai ver que ela vai interagir, eles são mais dificeis, mais quietos, paradinhos, parece que se tu não chega neles eles não chegam em ti, eles são mais assustados... (C7)

A Teoria de Enfermagem Humanística ${ }^{1}$ apresenta a possibilidade de relação de diálogo no estar com o outro que necessita de cuidado; expressa que o ser humano revela abertura ao encontro vivido de Enfermagem por meio de suas expressões. Acrescenta que a expressividade do ser e sua historicidade são interdependentes, visto que as vivências interferem nas suas relações, como ser no mundo com o outro. Assim, ao reconhecer que cada ser é único, o desenvolvimento da relação entre quem cuida será singular com cada criança.

Quanto à maneira única do ser humano de estar no mundo com o outro, cada um se expressa de forma única diante da disponibilidade para estabelecer uma relação de cuidado. Sendo assim, o ser expressa-se por meio das atitudes frente ao outro e ao mundo com base em suas vivências e experiências'.

A importância da relação autêntica para o encontro de cuidado dá-se, especialmente, no envolvimento entre quem cuida e a criança, manifestado pela presença ativa de ambos no tempo e espaço vividos, bem como pela reciprocidade ${ }^{11}$. Contudo, há situações experienciadas no mundo do cuidado em que aquele que cuida, mesmo apresentando abertura para estar-com, não consegue estabelecer uma relação com o outro, visto não ser possível a imposição, mas a necessidade de uma resposta livre ao convite para o encontro de cuidado.

Essas situações de não-reciprocidade não são entendidas como atitude de cuidado inautêntico, mas como um reflexo da alteridade, quando o outro precisa ser respeitado em sua maneira de ser no mundo, que pode se apresentar de forma diferente do esperado, como quando não ocorre a interação ${ }^{1}$.

É um olhar carente, um pedir socorro, um olhar triste, tipo 'me tire daqui', 'eu quero ir embora', ou 'hoje não preciso tomar esses remédios'. Como ele não sabe falar ele se expressa com o olhar. Acho que ele queria estar longe daqui: ambiente hospitalar não é bom para gente grande, então imagina para as crianças (C7)

A Teoria de Enfermagem Humanística ${ }^{1}$ traz a concepção de que é por meio da expressividade do humano que se desvela o modo de existir singular de cada um, considerando as vivências, únicas de cada ser. Diante de uma mesma situação, cada EU experiencia sentimentos e percepções que lhe são próprios.

A expressividade do ser humano não se dá somente por palavras, mas por silêncios, gestos, atitudes, entre outras formas de expressões ${ }^{1}$. E é neste mundo complexo e diversificado que o cuidado acontece. 0 encontro se estabelece e se desenvolve através do olhar, do toque e do dito e do nãodito $^{12}$, que mostram disponibilidade com o outro.

A Mimo de Vênus se isolava, não queria falar com ninguém, não queria comer nem tomar os remédios, $e$ às vezes não queria falar mesmo, queria ficar no mundo dela (...) é um mundo que as vezes a gente não faz parte... é o mundo dela, daquela criança... Não sei o que passava naquela cabecinha, a gente nem imagina o que se passa lá dentro... o que ela passou não deve ter sido fácil para uma criança (...) Uma criança que senta sozinha e chora (...) é triste, mas às vezes tu tinha que deixar... aquele tempinho dela... (C5)

A Teoria de Enfermagem Humanística ${ }^{1}$ apresenta a compreensão da singularidade do ser humano e a explica com base na existencialidade, que é única de cada ser, uma vez que cada um vivencia, experiencia, compreende e sente a si, o outro e o mundo de forma ímpar. Sendo assim, a criança se expressa às situações existenciais, devendo ser respeitada em sua totalidade. 0 cuidado autêntico acontece nestas premissas, sendo que, para ser com o outro, se faz necessário conhecê-lo, compreendê-lo e respeitá-lo, para, assim, disponibilizar-se a ajudá-lo e buscar estabelecer uma relação. Nesse sentido, pode-se entender o encontro de cuidado como um fazer parte do estar-com-o-outro-no-mundo. 


\section{Temporalidade e historicidade}

No encontro de cuidado, as vivências, experiências e sentimentos da criança são compreendidos como dimensões integrantes de sua existência como ser-no-mundo.

O cuidado é igual para todas as crianças (...) as crianças passam por tudo isso: são crianças que vivem a perda de pais, que internam e reinternam... Não deve ser nada fácil para eles, acho que se para um adulto é difíil, para uma criança deve ser pior ainda, acredito que eles tenham que amadurecer mais rápido que qualquer outra criança. Eles têm um estilo de vida diferente, falo em relação à medicação que eles têm que tomar, pela quantidade que eles têm que tomar por dia... eu acho que não deve ser nada fácil para eles também (C5)

0 ser humano desenvolve-se e torna-se mais em seu existir singular conforme as vivências e as experiências no que denominam como temporalidade e historicidade ${ }^{1}$. Essas dimensões existenciais são entendidas como essenciais ao existir humano, pois constituirão o ser. Assim sendo, são dimensões presentes no encontro de cuidado, visto que acontecem com base na totalidade existencial.

No estar-com, a criança em seu mundo-da-vida compartilhado desvela a compreensão de que há peculiaridades no encontro conforme a idade do ser, uma vez que, no viver com AIDS, algumas crianças têm conhecimento de sua condição sorológica, ao passo que outras não, configurando uma questão velada, percepção essencial para um cuidado autêntico, fundamentado na unicidade existencial do ser, o que remete ao reconhecimento e respeito às suas vivências.

A Mimo de Vênus já sabia mais ou menos que o caso dela era bem difícil, uma doença difícil. Ela perguntava o que tinha para gente, porque que tinha que estar ali, porque que tinha que fazer aquilo, porque que todos na familia dela tinham que tomar aqueles remédios... mas enquanto eles não sabem o que têm, eles se sentem igual aos outros. Enquanto eles são pequenos a gente vai engambelando... A Mimo de Vênus um pouco acreditava nas histórias que a gente contava, mas ela sempre tinha dúvida, porque sempre perguntava, continuava perguntando, perguntava para pessoas diferentes para ver o que as outras diziam... ela já tava percebendo que a medicação dela, o tratamento dela era diferente.. (C6)

A temporalidade do ser humano configura-se como integrante de seu existir, sendo compreendida como a configuração do tempo, não somente o cronológico que situa o ser desde seu nascimento até a morte, mas vivido em seu EU e nas relações com os outros e com o mundo. Neste tempo vivido há 0 encontro face-a-face e de reciprocidade entre os seres de relação, entre o EU e o $\mathrm{TU}^{9}$, quando se desvela a dimensão temporal, que diz respeito à inter-relação de vivências e experiências que compõem o existir.

Assim, ainda no que se refere à temporalidade, outra condição manifestada são as dificuldades que se apresentam quando a criança tem conhecimento de sua condição sorológica. 0 ser que cuida entende que quando as crianças não sabem que têm AIDS elas não se sentem diferenciadas.

Acho que enquanto as crianças são pequenas e não sabem o que está se passando com elas, elas se acham igual às outras crianças...(C6)

Acredito que as crianças não se percebem diferentes. Mas as crianças tão crescendo, e, com o tempo, talvez, depende do próprio contexto (C4)

Entende-se que a criança está em movimento de compreensão de si, do outro e do mundo, com base nas vivências oportunizadas em seu passado, presente e futuro. Essas três dimensões temporais interligadas possibilitam condições de existência. Assim sendo, o vivenciar do tempo presente está alicerçado nas experiências e nas vivências do tempo passado e nas possibilidades do tempo futuro, pois o ser humano existe em um contínuo vir-a-ser, ou, ainda, em um vivenciar de potencialidades para ser mais e possibilidades para estar melhor'.

\section{0 estar-com do ser-familiar}

A família configura-se como presença singular no cuidado, visto que é, essencialmente, no familiar que a criança busca atenção, segurança e ajuda.

Elas têm necessidade de estar com a familia delas, embora elas morem quilômetros de distância, elas amam a familia, elas querem estar junto, então a gente tem que entender 0 lado delas, elas valorizam muito, muito, muito isso (C1)

Percebe-se a necessidade da criança em estar-com, e na relação com sua familia é que vivencia a existencialidade e inicia o movimento de descobrir-se em um mundo compartilhado. Desvela-se que 0 mundo-da-família é referência no vir-a-ser na infância, na construção do mundo-da-vida da criança. Sendo que esta relação genuinamente singular ultrapassa laços sangüíneos ou situação econômica.

É para o familiar que dá os braços, é para o familiar que a criança volta, esse é o mundinho dessa criança, é isso que ela conhece, isso que ela aprendeu no meio de tantos outros sofrimentos, é no familiar que ela tem segurança, que ela tem laços, é o mundinho dela. A criança tá aqui há quase um mês e ainda não tem um laço com ninguém. A gente fica lá com ele, consola, conversa, mas ele não se apegou a ninguém... ele fica chorando enquanto a mãe não chega... (C7)

A família desvela-se nos depoimentos como sendo a configuração do mundo-da-vida da criança, no qual o familiar Ihe possibilitará reconhecimento, proteção e cuidado, o que se compreende com base na percepção de que é na família que a criança busca segurança e estabelece vínculos mais profundos. Entende-se a família como dimensão fornecedora de possibilidades no vir-a-ser na infância, dando oportunidades para a criança se desenvolver, em sua unicidade como ser-no-mundo e na singularidade de suas relações com os outros e com o mundo.

Encontra-se na Teoria de Enfermagem Humanística a compreensão de vivências que se desenvolvem entre seres humanos que necessitam das relações para alcançar a sua essencialidade ${ }^{1}$, entendendo de que o EU somente existe na presença do TU $^{9}$, no entre; na interação EU-TU ocorre a 
verdadeira com-unidade, entendida como reciprocidade do vínculo numa situação de chamado e resposta ${ }^{13}$.

0 estar lançado no mundo-do-hospital é compreendido como uma experiência de angústia e insegurança, diante da qual a criança busca referência e proteção do familiar como uma possibilidade para estar melhor. Percebe-se que é imprescindível compreender, respeitar e atender a essa necessidade existencial, uma vez que a família tem a possibilidade de oferecer uma segurança emocional, mantendo aspectos sadios da infância por meio de um vínculo com o mundo-da-vida integral da criança, auxiliando na sua adaptação ao mundo-do-hospital.

0 ser humano, como ser-no-mundo-com-o-outro, precisa ser compreendido e respeitado para, com isso, buscar um cuidado autêntico, partindo do encontro genuíno entre os seres, no compartilhar de escolhas livres e responsáveis, que vão ao encontro das vivências e experiências singulares ${ }^{1}$.

\section{O ser-familiar como um ser de cuidado}

0 familiar, além de ser o cuidador da criança, é um ser que necessita de cuidado e atenção, para ter a possibilidade de ajudar a criança na vivência do processo de adoecimento. Em tempos de AIDS, faz-se necessário refletir uma nova experiência no processo de cuidar: os pais das crianças, em sua maioria, vivem com AIDS.

Tem a situação de que a criança é doente, mas os pais também são (C7)

o cuidado tem que ser extensivo a quem cuida, a gente orienta, diz como que tem que fazer... (C3)

Os depoimentos apresentam uma situação característica da epidemia da AIDS, pais e filhos com AIDS, visto que os maiores índices de transmissão do HIV se dão na forma denominada vertical. Nesse sentido, o ser que cuida reconhece a necessidade de o cuidado abranger o familiar, tanto quanto o cuidado de si e o da criança.

Um dia a mãe da Mimo de Vênus me disse 'Ai, hoje eu tinha vontade de tirar a minha vida'. Eu disse: Deus o livre! Tu não pensa isso. Tens três filhos pra criar. Equem é que vai dar remédio pra eles? Tu vai voltar a tomar teus remédios, vai dar jeito de te conservar pros teus filhos (C8)

Uma mãe que tem AIDS às vezes não luta mais contra a doença, muitas mães que fazem tratamento dos filhos não fazem o delas, perde aquela ilusão pela vida, não quer tomar os remédios, não têm mais vontade de viver, vai se deprimindo e deixando coisas sem fazer direito (C3)

Desvela-se, pelo olhar dos cuidadores, a situação complexa experienciada no contexto do cuidado à criança, qual seja: a necessidade de a mãe aderir ao tratamento anti-retroviral (TARV), além de prestar os cuidados, inclusive medicamentosos, aos seus filhos. Percebe, diante disso, que, muitas vezes, as mães cuidam das crianças, mas não cuidam de si; assim, associam esta situação a uma desesperança e/ou desilusão pela vida. Esta "falta de vontade de viver" vai ao encontro da necessidade de cuidado.

Desvela-se a preocupação, que emerge do encontro de cuidado, com a família da criança com AIDS. 0 ser que cuida demonstra perceber que o familiar, além de experienciar o processo de adoecimento da criança, que precisa de sua atenção, cuidado e afeto, vivencia a angústia de também estar doente e ter que se cuidar. Nessa vivência, o ser que cuida percebe que o familiar expressa a possibilidade de desistir, trazendo velado um pedido de ajuda. Sendo assim, faz-se necessário cuidar do familiar, visando a oferecer ajuda por meio do compartilhar e do estar-junto'.

Os pais representam o elo da criança com o mundo, porém faz-se necessário perceber o cuidado em âmbito maior, visto que o familiar ao vivenciar o processo de adoecimento da criança experimenta sentimentos de inquietação, insegurança, medo, angústia, entre outros, que são compreendidos como integrantes da existencialidade do ser e que configuram as relações genuínas como ser-no-mundo-com-o-outro ${ }^{1}$.

Situações conflitantes... quando tem problemas de relacionamentos com os pais, essas são as relações conflitantes, de não-adesão ao tratamento, de dificuldades de relacionamento com a equipe (C5)

Percebe-se que o cuidado inicia-se na abertura à atitude de ajuda ${ }^{1}$ e desenvolve-se no compartilhar de vivências, sentimentos, dificuldades e inseguranças do ser que é cuidado. Configura-se, assim, o encontro autêntico de Enfermagem, do qual decorrem inquietações, angústias e dificuldades, vivenciadas por ambos os seres, e, por meio do ser-com genuíno, busca-se ultrapassar estas situações conflitantes.

Tem mães que não tomam medicação, cuidam da criança e não cuidam delas, inclusive a mãe que não fazia o tratamento faleceu e a criança ficou. Quando a mãe faleceu a gente começou cuidar da criança e viu que ela também não tomava as medicações, escondia debaixo do travesseiro, colocava no lixo... (C6)

Diante das experiências de dificuldades no cuidar, a comunidade revela uma possibilidade de ajuda para o ser humano doente, por meio do compartilhar e do respeito mútuo entre quem cuida e quem é cuidado ${ }^{1}$.

Compreende-se que para alcançar a reciprocidade, ser que cuida e ser que é cuidado necessitam saber ouvir, não somente 0 que é dito, mas aquilo que se quer dizer. Os significados estão no modo de ser: olhar, atitudes, palavras, silêncios. Por vezes, esse significado pode estar velado, como na não-aceitação do tratamento prescrito; podendo expressar um pedido de ajuda.

A Mimo de Vênus cuidava dos irmãos, quando a irmãzinha internou e não queria tomar remédio, ela vinha e dava remédio pra ela. Ela se impunha pra a irmã: 'Toma esse remédio, tu tem que tomar pra ir pra casa'. Mas, às vezes, ela não queria tomar. Ela tirava uma temporada colocando todos os remédios no vaso e puxando descarga. As mães das outras crianças da enfermaria contavam que ela botava tudo debaixo do travesseiro e dizia que tinha tomado. As gurias davam a medicação pra ela na seringa, ela jogava tudo nas fraldas e botava no lixo. Ela tinha vários jeitos, várias artimanhas pra não tomar a medicação. Se ninguém visse, pensava que ela tinha tomado o remédio. Mas ela teve mal, foi até pra UTI. Tudo porque ela não tomava as medicações (C8)

No encontro de cuidado, mesmo diante de dificuldades, 0 ser que cuida precisa ter clareza e estar comprometido com o objetivo do cuidar - o estar-melhor - e desenvolver a atitude 
de ajuda com responsabilidade. Para oferecer a presença genuína, o ser que cuida precisa ter consciência da importância do seu estar-com ${ }^{1}$. A presença e a intersubjetividade são qualidades de estar do ser que cuida, e para alcançá-las requer um refletir sobre seu ser, saber e fazer ${ }^{14}$, e os significados fundamentais do cuidado, para, assim, buscar um agir consciente.

As mães dessas crianças fazem menos questão de se envolver, porque é difícil dizer que tem AIDS, então elas se fecham e não dizem nada, até não têm que dizer mesmo, as pessoas não têm que saber (...) se tu tá numa enfermaria e vai dizer que o fulano tem AIDS... acaba que tem sempre gente que não vai querer chegar perto, vai achar que porque tá respirando o mesmo ar corre o perigo de se contaminar, é a desinformação. Então, acho que o familiar deixa a coisa num parâmetro de afastamento, até para proteger a criança dessas atitudes (C4)

0 afastamento do familiar das outras pessoas, no intuito de proteger a criança, reforça o contexto da epidemia que traz intrínseco mitos e estigmas, evidenciando (in)compreensão da doença que atinge o ser em sua existencialidade. Esta configura um relacionamento EU-ISSO ${ }^{9}$, na qual não há o compartilhar ou a reciprocidade, essenciais para o cuidado humanístico.

Faz-se importante ressaltar que o relacionamento EU-ISSO é também uma atitude autêntica. É por meio desta que o ser pode compreender as aquisições científicas e técnicas da humanidade. A partir do EU-ISSO, que se caracteriza pela experiência e utilização, confere-se o caráter unidirecional, constrói-se o saber; ao passo que o EU-TU desenvolve o ser ${ }^{9}$. Assim, ambas as atitudes conferem autenticidade existencial ${ }^{1}$.

Este modo de estar com o ser, com base em sua condição sorológica, vai de encontro ao que a Teoria de Enfermagem Humanística entende como com-unidade, como um estar-junto ${ }^{1}$. Em contraposição a este modo de relação apresentado pelas teoristas, 0 discurso a seguir relata situações de (des)cuidado no âmbito familiar.

Quando a vó, por parte de pai, soube que Mimo de Vênus tava doente cuidou dela por quase um mês. Mas quando descobriram que era HIV, a velha foi embora e nunca mais... A mãe dizia que a vó tinha medo de cuidar as crianças, medo de pegar a doença. Não sei se as crianças percebiam que a vó tinha medo de pegar a doença deles. Mas a Mimo de Vênus dizia que a vó não gostava deles, que não dava carinho. Só tinha uma tia que cuidava, foi quem levou as crianças quando a mãe morreu. A mãe sempre dizia que o pai tinha horror da Mimo de Vênus. O homem só gostava da pequena; da Mimo de Vênus e do filho ele não gostava, ele não dava carinho nenhum pros dois, nem remédio (C8)

No cuidado à criança com AIDS, percebe-se que a família expressa uma não-aceitação a estas crianças em função da doença que possuem, o que se associa ao medo de se infectar, que culmina em atitude de descuidado, o qual está vinculado à necessidade que a criança tem da presença do familiar que a abandona e, ainda, percebe que o mesmo tem medo delas, a exemplo da Mimo de Vênus, que expressava que a avó não gostava dela e de seus irmãos e que não lhes dava carinho.
Ainda, no que se refere a essa não-aceitação do ser, com base em sua condição sorológica, tem-se a percepção quanto à decisão da mulher com HIV de ser mãe, considerando, nessa situação, a possibilidade de transmissão do vírus para a criança:

AIDS é uma doença que não deveria ser para crianças. Mães com essa doença não deveriam ter filhos. Tinha que fazer rastreamento: é doente, não pode ter filho. Eles vão estar vivos para ver a criança crescer? (C7)

Acho uma tristeza! Eles sabem que têm a doença e fazem mais de um filho. Quando é um acidente, eles não sabem que têm o vírus, só descobrem depois, tudo bem, mas, às vezes, eles sabem e fazem dois, três filhos. É uma irresponsabilidade, uma malvadeza (C8)

Esta (im)possibilidade de engravidar para mulher com AIDS vai ao encontro de uma percepção limitada à doença ${ }^{1}$, que culmina em julgamentos e preconceitos, configurando uma situação de cuidado inautêntico.

As teoristas acreditam que o julgamento e o preconceito interferem na inter-relação e, conseqüentemente, no desenvolvimento do cuidado, visto que se refere, essencialmente, ao respeito ao outro como ser humano ${ }^{11,15}$.

Neste sentido, faz-se referência aos estigmas relacionados à epidemia da AIDS, como a (in)certeza que é colocada em questão quanto à finitude humana ${ }^{16}$. Sob o olhar da Teoria de Enfermagem Humanística, que se fundamenta na existencialidade do humano, independentemente da doença, essa finitude será sempre uma inquietação e uma certeza, pois todo ser um dia irá morrer, mas esse preceito não pode determinar as suas decisões nem 0 julgamento ou discriminação dos outros.

A responsabilidade na relação EU-TU9 só existe na reciprocidade, na resposta a um pedido de ajuda, um chamado de cuidado ${ }^{1}$. A resposta a uma interpelação supõe a situação prévia de reconhecimento do outro em sua alteridade ${ }^{17}$.

A responsabilidade do cuidado se expressa no modo de estar-com ${ }^{1}$; neste sentido, a solidariedade é um modo de estar com o ser e deixá-lo ser, não conforme se gostaria que fosse, mas como realmente é, no existir de suas escolhas ${ }^{18}$.

\section{APROPRIAÇÃO DOS SIGNIFICADOS: PERSPECTIVA PARA O CUIDADO DE ENFERMAGEM}

Ao enfocar o cuidado de Enfermagem, destacou-se a compreensão da criança com AIDS como um ser-no-mundocom-o-outro. Compreendeu-se que a criança com AIDS não se difere das outras crianças, uma vez que a doença faz parte do existir e seu mundo-da-vida não se restringe a isto. A criança é entendida na singularidade de suas experiências e vivências, em seu processo de crescimento e desenvolvimento.

A criança necessita experienciar a infância permeada do brincar, sorrir e aprender, sendo essenciais ao seu existir. Portanto, ao percebê-la como doente, o ser que cuida não deve limitá-la em suas potencialidades, restringido o direito existencial de vir-a-ser. Assim, a necessidade de adesão ao TARV e profilático, e o mundo-do-hospital, como integrantes do mundo-da-vida da criança com AIDS, não devem ser 
limitadores da infância, mas possibilidades de ajuda para o seu estar-melhor, mesmo com uma doença que não tem cura.

Compreender a criança em sua existencialidade revela uma possibilidade de autenticidade no cuidado de Enfermagem, buscando ir à procura do humano em uma transação intersubjetiva que não esteja limitada pelo patológico e pelo tecnológico. A partir da compreensão do ser-no-mundo, é possível trilhar novos caminhos para construir um cuidado voltado para o mundo-da-vida da criança e o mundo-da-família, não limitado ao mundo-do-hospital. No qual a sensibilidade e a solicitude sejam cultivadas, envolvendo não apenas um corpo ou uma doença, mas um ser integral ${ }^{8}$.

Este modo de cuidar oferece a possibilidade de atenção ao expressar da criança, pode ser uma forma de demonstrar sua necessidade do outro ou de pedir ajuda, muitas vezes não percebida no mundo-do-hospital.

Neste cuidar constrói-se um mundo compartilhado, que possibilita fazer parte do mundo-da-vida da criança. Uma condição contrária de cuidado limita a compreensão do dito e do não-dito, o que confere inautenticidade no encontro de cuidado e desvela um modo de estar-com preso à doença, sem atentar para o velado na expressividade.

0 modo como a criança se mostra remete a sua historicidade e temporalidade que, no viver com AIDS, são permeadas pela perda dos pais, pelas reinternações hospitalares, necessidade de adesão ao TARV, acompanhamento de saúde, entre outras.

Na compreensão dessas vivências, apreende-se que a criança de menor faixa etária não demonstra ter conhecimento do diagnóstico, não tendo consciência dos estigmas da AIDS e não se percebendo diferente das crianças com outras patologias. Por sua vez, as crianças de maior faixa etária demonstram perceber que a doença que possuem as diferencia, em virtude, principalmente, dos seus medicamentos e dos seus familiares, que muitas vezes fazerem uso dos mesmos. Demonstra-se ser o mundo-do-hospital parte do mundo-da-vida na sua infância. Estas condições, dentre outras, culminam em questionamentos do que é velado, visto que a maioria das crianças vive sobre o "pacto do silêncio"19, p.91 , não lhes sendo revelado o diagnóstico de AIDS.

Essa revelação não deve ser feita isoladamente por decisão da equipe de saúde, faz-se necessário o consentimento da família. Na maioria das vezes, a família demonstra dificuldades na revelação, temem que a criança se revolte ou quebre 0 pacto de silêncio, expondo a condição sorológica da família, estando vulnerável às situações de discriminação e preconceito.

Este desafio está sendo vivenciado, atualmente, nos serviços de saúde que atendem, especialmente, as crianças que se infectaram por transmissão vertical do HIV, visto que estão alcançando uma nova fase do desenvolvimento humano, como a primeira geração infectada desde o nascimento por este vírus e que está adolescendo com AIDS. Tem-se, portanto, o paradoxo: a necessidade de revelar, exposta, especialmente, pelo despertar da sexualidade e pela necessidade de compartilhar a adesão ao TARV, versus o despreparo para esta nova situação que a epidemia apresenta.

Compreende-se que o estar-com do ser-familiar é essencial no encontro de cuidado de Enfermagem para o estar-melhor da criança. Sendo assim, a família é compreendida como presença indispensável, considerando-se que transcende laços sangüíneos. A criança tem necessidade de estar junto de seus familiares, tendo na unidade familiar sua referência, proteção, segurança emocional, e é com essa que mantém aspectos sadios da infância. Assim, compreende-se que o mundo-da-família configura-se, na maioria das vezes, como o próprio mundo-davida da criança. "A família é o universo da criança, sob a sua intermediação passa a existir como ser no mundo"8, p.147. No contexto familiar, a criança encontra possibilidades de crescer e se desenvolver, eé no mundo-da-família que se sente protegida e segura.

A relação entre o ser que cuida, o familiar e a criança revela autenticidade no estar em com-unidade, como uma presença disponível para ajudar ao outro, respeitando-o em sua existencialidade. Este modo de ser com o outro se mostra genuíno na reciprocidade, que se estabelece quando um ser pede ajuda, de forma verbal ou não-verbal, e o outro responde, revelando o que se denomina chamado e resposta ${ }^{1}$.

Assim, a relação EU-TU ${ }^{9}$ pode ser compreendida como a interação entre o ser que cuida e o binômio criança-família, pela qual se tem a possibilidade de escolhas livres e responsáveis para ser mais. Neste sentido, há duas categorias básicas na maneira de ser da família no mundo-do-hospital: a presença e o sofrimento. A presença dos pais é segurança para criança, família e equipe, ao mesmo tempo em que passam a viver a angústia de estar vivenciando dores, incertezas e a finitude. Assim a doença transforma a maneira de sentir, de ver e ser no mundo ${ }^{8}$.

É fundamental compreender o ser-familiar como um ser de cuidado, visto que necessita de ajuda para adquirir conhecimentos e preparo emocional para estar com a criança no processo de adoecimento. Soma-se o fato de que os pais das crianças com AIDS, em sua maioria, também são soropositivos e necessitam de atenção à sua saúde.

No encontro de cuidado com o familiar que vive com AIDS, percebe-se que muitos, em especial as mães, se esmeram em cuidar de seus filhos e se esquecem da atenção à sua própria saúde; sendo que um cuidado essencial é a adesão ao TARV. Entende-se, assim, que a vulnerabilidade da mãe e a da criança, desde a infecção até o risco de adoecimento, coexistem no viver com AIDS ${ }^{20}$. Este entendimento se estabelece na concepção de que a mãe representa a referência para existencialidade da criança e que esta representa a essência do seu mundo-da-vida daquela. Soma-se a compreensão de que a família é singular para a criança, em seu processo de vir-a-ser, na vivência do adoecimento e na experiência no mundo-do-hospital. Assim, o binômio mãe-filho(a) é essencial no vivenciar do adoecimento, e o cuidado voltado a este EU-TU possibilitará uma adaptação e reestruturação da existência da criança e de sua família.

Nesse sentido, com base em vivências de cuidado de Enfermagem, percebe-se que as mães acreditam que não há outra pessoa melhor que elas para cuidar das crianças; porém não consegue assumir a adesão ao TARV de seus filhos e a sua própria adesão. Soma-se o paradoxo de que a criança representa vida, enquanto a AIDS, a doença. 
Assim, uma maneira que as mães encontram de conviver com essa questão paradoxal é proporcionando tudo o que está ao seu alcance para o melhor de seus filhos, tentando encontrar a melhor forma de cuidar, como se a cura estivesse em suas mãos; esquecem, muitas vezes, de sua própria condição sorológica²1. Partem do princípio que o cuidado é a melhor forma de a criança 'negativar', muitas vezes excedendo o padrão considerado normal das práticas de cuidado, sendo justamente este excesso de atenção que alivia das mães a "culpa" da doença dos filhos ${ }^{22}$.

Como uma forma de cuidado, os familiares se distanciam das outras pessoas no intuito de se proteger e proteger a criança de atitudes de discriminação. Esta atitude ajuda a

\section{Referências}

1. Paterson J,Zderad L. Enfermería humanística. México (DF): Limusa; 1979.

2. Ministério da Justiça (BR). Lei $n^{\circ} 9610$, de 19 de fevereiro de 1998. [on-line] Lei dos Direitos Autorais. [citado nov. 2002] Disponível em: http://www.mdic.gov.br.

3. Boemer MR. A condução de estudos segundo a metodologia de investigação fenomenológica. Rev Latino-am Enfermagem 1994 jan; 2(1): 83-94.

4. Simões SMF, Souza IEO. Um caminhar na aproximação da entrevista fenomenológica. Rev Latino-am Enfermagem 1997 jul; 5(3): 13-7.

5. Carvalho AS. Metodologia da entrevista: uma abordagem fenomenológica. Rio de Janeiro (RJ): Agir; 1987.

6. Ricoeur P. O conflito das interpretações. Rio de Janeiro (R): Linargo; 1978.

7. Crossetti MGO. Processo de cuidar: uma aproximação à questão existencial na enfermagem [tese de doutorado]. Florianópolis (SC): Departamento de Enfermagem/UFSC; 1997.

8. Motta MGC. 0 ser doente no tríplice mundo da criança, familia e hospital: uma descrição fenomenológica das mudanças existenciais [tese de doutorado]. Florianópolis (SC): Departamento de Enfermagem/UFSC; 1997.

9. Buber M. Eu e Tu. São Paulo (SP): Moraes; 1977.

10. Buber M. Sobre a comunidade. São Paulo (SP): Perspectiva; 1987.

11. Meleis Al. Josephine Paterson e Loreta Zderad: theory description. In: Meleis Al. Theorical nursing: development and progress. 2nd ed. Philadelphia(USA): JB. Lippincott Company; 1991.

12. Oliveira ME. Vivenciando uma experiência amorosa de cuidado com mães e seus recém-nascidos pré-termo. Rev Eletr Enferm [periódico on line] 2001 jul; [citado 17 jul 2003]; 2(2): [aprox. 5 telas]. Disponivel em http://www.fen.ufg.br/revista.

13. Von Zuben NA. Introdução. In: Buber M. Eu e Tu. São Paulo (SP): Moraes; 1977.

14. Paula CC, Crossetti MGO. 0 acontecer do cuidado de enfermagem ao ser-criança que convive com aids: ser, saber e fazer compartilhado. Rev Gaucha Enferm 2005 abr; 26(1): 102-14.

15. Brouse $S$, Laffrey $S$. Paterson and Zderad's humanistic nursing framework. In: Fitzpatrick J, Whali A. Conceptual models of nursing: analysis and application. Norwalk: Appleton \& Lange; 1989. criança a conviver com as dificuldades de inclusão social. Porém, com o transcorrer do desenvolvimento infantil a criança passa a perceber formas de preconceito nos serviços de saúde, na escola, na comunidade e, muitas vezes, entre a própria família que apresenta dificuldades de convívio com pessoas soropositivas.

Todo esse contexto vivenciado pelas crianças e suas famílias revela a necessidade de ajuda à criança e à família no processo de readaptação ao seu mundo-da-vida. Esta ajuda pode ser desenvolvida em um Cuidado Humanístico ${ }^{23}$, por uma relação de compreensão, respeito, diálogo e atitudes autênticas e comprometidas com 0 estar-melhor da criança ${ }^{24}$, não limitado à sua condição sorológica.

16. Paula CC, Crossetti MGO. 0 modo de cuidar no encontro com o ser-criança que convive com aids: 0 experienciar da finitude e da ética. Texto\&Contexto Enferm 2005 abr; 14(2): 193-201.

17. VonZuben NA. O primado da presença e o diálogo em Martin Buber.[texto on-line) Anais do Encontro Internacional de Filosofia da Linguagem; 1981 ago; Campinas (SP), Brasil:; Campinas SP):UNICAMP 1981. [citado out 2003] Disponivel em :http://mww.fae.unicamp.br/vonzuben/presenca.html.

18. Pessini L. Aids: um apelo à vida. In: Pessini L, Bachifontaire CP. Problemas atuais de bioética. $3^{\text {a }}$ ed. São Paulo (SP): Loyola; 1991.

19. Padoin SMM, Rosa GM, Tappes C, Paula CC. Acompanhamento multidisciplinar de crianças HIV/AIDS e seus familiares e/ou cuidadores - perfil epidemiológico da criança com HIV/AIDS assistida no serviço de doenças infecciosas pediátricas do HUSM, no período de 1999-2000. Santa Maria (RS):UFSM; 2001. Relatório de Projeto de Pesquisa e Extensão PIBIC-CNPq.

20. Paiva V, Leme B, Nigro R, Caraciolo J. Lidando com a adesão: a experiência de profissionais e ativistas na cidade de São Paulo. In: Teixeira PR, Paiva V, Shimma E, organizadores. Tá difícil de engolir? Experiências de adesão ao tratamento anti-retroviral em São Paulo. São Paulo (SP): NepAIDS; 2000.

21. Paula CC, Padoin SMM, Vernier EN. 0 cuidado de enfermagem na educação em saúde: um meio de interagir e refletir o que é sercriança no mundo de hoje [monografia acadêmica]. Santa Maria (RS): Departamento de Enfermagem/UFSM; 2002.

22. Padoin SMM. Em busca do estar melhor do ser-familiar e do sercom aids [dissertação de mestrado]. Florianópolis (SC): Departamento de Enfermagem/UFSC; 1998.

23. Paula CC, Schaurich D, Padoin SMM, Crossetti MGO. 0 cuidado como encontro vivido e dialogado na teoria de enfermagem humanística de Paterson e Zderad. Acta Paul Enf 2004 out; 17(4): 425-31.

24. Schaurich D, Paula CC, Padoin SMM, Motta MGC. Utilização da teoria de enfermagem humanística de Paterson e Zderad como possibilidade de prática em enfermagem pediátrica. Esc Anna Nery Rev Enferm 2005 abr; 9(1): 265-70.

\section{Nota}

aEsse artigo originou-se da dissertação de Mestrado "Encontro de Cuidado, Vivido e Dialogado, da Equipe de Enfermagem com o Ser-Criança que Convive com AIDS", defendida em 2003, no Programa de Mestrado em Enfermagem da Universidade Federal do Rio Grande do Sul. 